\title{
Characterization of an intertidal zone metagenome oligoribonuclease and the role of the intermolecular disulfide bond for homodimer formation and nuclease activity
}

Yvonne Piotrowski, Kristel Berg, David Paul Klebl ${ }^{\dagger}$, Ingar Leiros and Atle Noralf Larsen

Department of Chemistry, Faculty of Science and Technology, SIVA Innovation Centre, UiT - The Arctic University of Norway, Tromsø, Norway

\section{Keywords}

crystal structure; homodimer; metagenome; nuclease activity; oligoribonuclease; RNA

\section{Correspondence}

A. N. Larsen and Y. Piotrowski, Department of Chemistry, Faculty of Science and Technology, SIVA Innovation Centre, UiT The Arctic University of Norway, Sykehusvegen 23, Tromsø 9037, Norway Tel: +47 77644478 (ANL); +47 776233 58 (YP)

E-mails: atle.larsen@uit.no (ANL); yvonne.piotrowski@uit.no (YP)

\section{${ }^{\dagger}$ Present address}

School of Biomedical Sciences, Faculty of Biological Sciences, Astbury Centre for

Structural and Molecular Biology, University of Leeds, Leeds, LS2 9JT, UK

(Received 6 August 2019, accepted 15

August 2019)
The gene encoding MG Orn has been identified from a metagenomic library created from the intertidal zone in Svalbard and encodes a protein of 184 amino acid residues. The $m g$ orn gene has been cloned, recombinantly expressed in Escherichia coli, and purified to homogeneity. Biochemical characterization of the enzyme showed that it efficiently degrades short RNA oligonucleotide substrates of $2 \mathrm{mer}$ to $10 \mathrm{mer}$ of length and has an absolute requirement for divalent cations for optimal activity. The enzyme is more heat-labile than its counterpart from E. coli and exists as a homodimer in solution. The crystal structure of the enzyme has been determined to a resolution of $3.15 \AA$, indicating an important role of a disulfide bridge for the homodimer formation and as such for the function of MG Orn. Substitution of the Cys110 residue with either Gly or Ala hampered the dimer formation and severely affected the enzyme's ability to act on RNA. A conserved loop containing His128-Tyr129-Arg130 in the neighboring monomer is probably involved in efficient binding and processing of longer RNA substrates than diribonucleotides.
Oligoribonuclease (Orn) is assumed to originate from eukaryota and is present in almost all eukaryotes [1,2]. In bacteria, and based on sequenced bacterial genomes, orn is mainly distributed in beta- and gammaproteobacteria and firmicutes [1]. Orn is a processive $3^{\prime}-5^{\prime}$ exonuclease that converts small oligoribonucleotides to monoribonucleotides and is important for mRNA decay in cells [3]. Studies in Escherichia coli show that Orn is essential for the viability of the bacteria [3], while Pseudomonas aeruginosa cells remain viable in the absence of Orn [4]. Interestingly, the human Orn homologue is able to degrade both small single-stranded RNA and DNA molecules in vitro and the authors suggest a role of human Orn in cellular nucleotide recycling [5].

In recent years, several studies of Orn in $P$. aeruginosa have broadened the view on the role(s) of Orn in

\footnotetext{
Abbreviations

CMP, cytidine 5'-monophosphate; MBP, maltose-binding protein; OD600, optical density at 600 nm; PAA, polyacrylamide; PDB, Protein Data Bank; pNP-TMP, p-nitrophenyl ester of thymidine 5'-monophosphate; TEV, tobacco etch virus.
} 
bacteria. Depletion of Orn leads to accumulation of small RNA molecules in cells, and these can serve as primers for transcription initiation and lead to global alterations in gene expression [6]. Orn is also demonstrated to play a central role in intracellular turnover of the bacterial second messenger cyclic-di-GMP with implications for bacterial motility, virulence, and biofilm formation [7,8]. A recent study showed that an orn mutant of $P$. aeruginosa displayed reduced cytotoxicity mainly by affecting the type III secretion system, further indicating an important role of Orn in bacterial pathogenesis [9]. Furthermore, Chen and coworkers showed that a $\Delta$ orn mutant became highly susceptible to the antibiotic ciprofloxacin, indicating a novel role in antibacterial drug resistance [10].

Orn is a member of the DEDDh superfamily of exoribonucleases and contains four sequence motifs unique to oligoribonucleases [2]. It is a small protein of approximately $20 \mathrm{kDa}$ and requires divalent cations for nuclease activity, preferably $\mathrm{Mn}^{2+}[5,11,12]$. The $E$. coli enzyme exists as a homodimer in solution $[12,13]$. Through gel filtration experiments, the human homologue of $E$. coli Orn is in one study shown to be a tetramer in solution [5], whereas another study indicates the enzyme to be a homodimer [12]. The E. coli enzyme is characterized as heat-stable, has a half-life of $60 \mathrm{~min}$ at $65{ }^{\circ} \mathrm{C}$, and still has residual activity after 10 -min incubation at $100{ }^{\circ} \mathrm{C}$ [11]. The human enzyme is also quite thermostable and has a temperature optimum for nuclease activity around $50{ }^{\circ} \mathrm{C}$ [5]. Datta and Niyogi [14] showed that E. coli Orn has a higher affinity for longer chain substrates than smaller substrates, but the reaction rate was inversely proportional to the length of the chain. The nuclease activity of the human Orn homologue is also inversely proportional to the length of the single-stranded substrate [5]. Analysis of the kinetic data of human Orn indicates similar $K_{\mathrm{m}}$ values for short single-stranded RNA and DNA but degrades short RNA about fourfold more efficiently than ssDNA [5].

Crystal structures of Orn show that they are closely related and topologically arranged into an $\alpha+\beta$ fold containing 5-6 $\beta$-strands and 9-10 $\alpha$-helices (PDB 2GBZ: Xanthomonas campestris, PDB 1J9A: Haemophilus influenzae, PDB 2IGI: E. coli, PDB 3TR8: Coxiella burnetii, PDB 5CY4: Acinetobacter baumannii). Despite several deposited Orn structures, it is yet unclear how Orn achieves the apparent processive oligoribonucleotide cleaving mechanism, but formation of a stable homodimer is indicated to be important [15]. In the $X$. campestris Orn structure (PDB 2GBZ), it is shown that Orn forms a dimer in the crystal through crystallographic symmetry. From the structural analysis, it was shown that hydrophobic interactions as well as several hydrogen bonds (H-bonds), salt bridges, and a disulfide bond contribute to the formation of a stable homodimer. A very recent publication showing among others an Orn with two uridine molecules bound in the RNA substrate binding site also provides further evidence that hydrophobic interactions, salt bridges, and $\mathrm{H}$-bonds are important for dimer formation [16].

In this study, we have recombinantly produced, characterized, and determined the three-dimensional crystal structure of an arctic marine oligoribonuclease, named MG Orn. We further wanted to investigate the role of the intramolecular disulfide bond connecting the two MG Orn monomers, and our results suggest that this disulfide bond is essential for the formation of a functional homodimer and therefore also the ability of the enzyme to degrade small oligoribonucleotides. We also report the ability of MG Orn to act on longer RNA molecules. Finally, we indicate the involvement of a conserved His-Tyr-Arg loop in the neighboring monomer in binding of these longer (up to 10 mer) RNA substrates.

\section{Results}

The metagenomic oligoribonuclease (MG Orn) described in this paper consists of 184 amino acid residues. The protein has been recombinantly produced with an N-terminal $\mathrm{His}_{6}$-MBP-tag followed by a cleavage site for the tobacco etch virus (TEV) protease. After hydrolytic removal of the N-terminal tag, four amino acid residues (Gly-Ser-Phe-Thr) remain at the $\mathrm{N}$ terminus of $\mathrm{MG}$ Orn due to the recognition site of the protease. Numbering of the amino acid residues within this paper will be according to the protein sequence of MG Orn, that is, excluding the additional amino acid residues of the tag-removal reaction.

\section{Phylogenetic analysis/sequence analysis}

A phylogenetic tree based on the maximum likelihood method places MG Orn and the close homologue Arenicella xantha Orn in a distinct clade from the other Orn homologues (Fig. 1), as expected from the high sequence identity compared to other Orn homologues $(94 \%$ versus $50-60 \%)$. These two homologues branch out early, just after the shared common gammaproteobacteria ancestor, but their origin is a rather recent event. The statistical bootstrap support value of 100 strongly indicates that MG Orn originates from a species within the Arenicellales order, possibly Arenicellas or another close relative. 


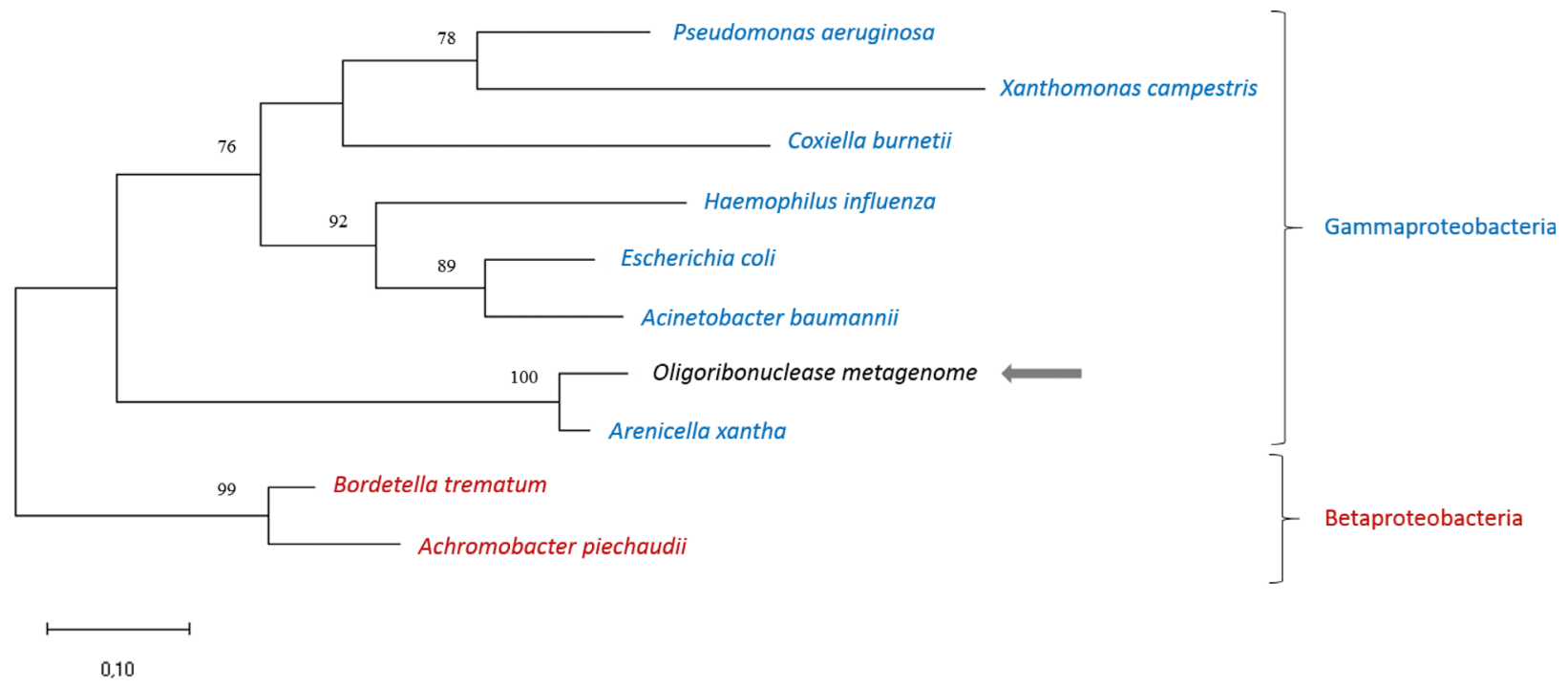

Fig. 1. Phylogenetic relationship of MG Orn protein with selected Orn homologues from gamma- and betaproteobacteria. Node numbers indicate bootstrap support values, with only values above 50 shown. The investigated metagenome sequence is marked with a gray arrow. The tree is drawn to scale, with branch lengths measured in the number of substitutions per site. The sequences were obtained from GenBank with the following accession numbers: WP_113955167.1 (Arenicella xantha), WP_011037314.1 (Xanthomonas campestris), RQB22498.1 (Pseudomonas aeruginosa), WP_005770781.1 (Coxiella burnetii), SST03775.1 (Acinetobacter baumannii), WP_021035403.1 (Haemophilus influenzae), WP_042004351.1 (Escherichia coll), WP_025512385.1 (Bordetella trematum), and WP_006218241.1 (Achromobacter piechaudii).

\section{Biochemical/biophysical characterization}

Size-exclusion experiments were performed to investigate whether MG Orn was monomeric or dimeric in solution. MG Orn eluted as a single peak corresponding to a protein with a molecular weight of $41 \mathrm{kDa}$ (Fig. 2), clearly indicating that MG Orn existed as a dimer in solution. The effect of divalent cations $\left(\mathrm{Mg}^{2+} / \mathrm{Mn}^{2+}\right)$ and $\mathrm{pH}$ on the nuclease activity of MG Orn has been determined using the $p$ NP-TMP activity assay (see Methods). MG Orn showed an absolute requirement for a divalent metal ion, with $\mathrm{Mn}^{2+}$ being clearly preferred over $\mathrm{Mg}^{2+}$ (Fig. 3A,B). Furthermore, MG Orn possessed a quite narrow $\mathrm{pH}$ range for optimal activity of $\mathrm{pH}{ }^{8}-9$ with an apparent optimum at pH 8.5 (Fig. 3C).

The effect of various salt concentrations on the nuclease activity of MG Orn was analyzed using the gel-based nuclease activity assay. MG Orn showed significant salt $(\mathrm{NaCl})$ tolerance using 7mer RNA as substrate, and robust hydrolytic activity was observed in the presence of up to $250 \mathrm{~mm} \mathrm{NaCl}$. There is still some residual activity observed in the presence of $500 \mathrm{~mm} \mathrm{NaCl}$ with activity gradually declining up to $2 \mathrm{M} \mathrm{NaCl}$ (Fig. 3D). Using the dinucleotide analogue $p$ NP-TMP as substrate ( $p$ NPTMP assay), MG Orn possessed even higher salt tolerance and little effect on nuclease activity was observed even at $2 \mathrm{M} \mathrm{NaCl}$ (results not shown).
To assess the thermal stability of MG Orn, the enzyme was preincubated at different temperatures for 15 min and residual activity was measured using the $p$ NP-TMP activity assay. MG Orn was rapidly inactivated at temperatures above $48{ }^{\circ} \mathrm{C}$, with a half-life of about $15 \mathrm{~min}$ at $50^{\circ} \mathrm{C}$ (Fig. 4).

The 7mer RNA substrate 7 mer-62OMe (5'-[FAM] $\mathrm{CCCCC}[\mathrm{mC}] \mathrm{C}-3^{\prime}$ ) was used to investigate the directionality of MG Orn. The substrate contains a methyl group at the $2^{\prime}$ hydroxyl of the ribose at $\mathrm{C}^{6}$. This $2^{\prime}$ O-methylation blocks ribonuclease function. Nuclease activity proceeding in $3^{\prime}-5^{\prime}$ direction will result in one 6 mer RNA with the fluorophore FAM linked to the $5^{\prime}$ end and one unlabeled cytidine $5^{\prime}$-monophosphate (CMP). If the nuclease proceeds in $5^{\prime}-3^{\prime}$ direction, the substrate will be cleaved into one FAM-labeled CMP, four unlabeled CMPs, and one unlabeled CDP. MG Orn proceeds in $3^{\prime}-5^{\prime}$ direction as in all reactions a band just below the RNA substrate (7mer with $2^{\prime}$-OMe) can be detected, indicating a FAM-labeled 6mer RNA (Fig. 5A). Using $5^{\prime}$ FAM-labeled 5mer RNA as substrate, MG Orn effectively degraded the substrate to monoribonucleotide products, further proving its $3^{\prime}-5^{\prime}$ directionality (Fig. 5B). MG Orn was also able to degrade short single-stranded DNA (5mer and 10mer) although with much lower efficacy than with RNA (results not shown). 


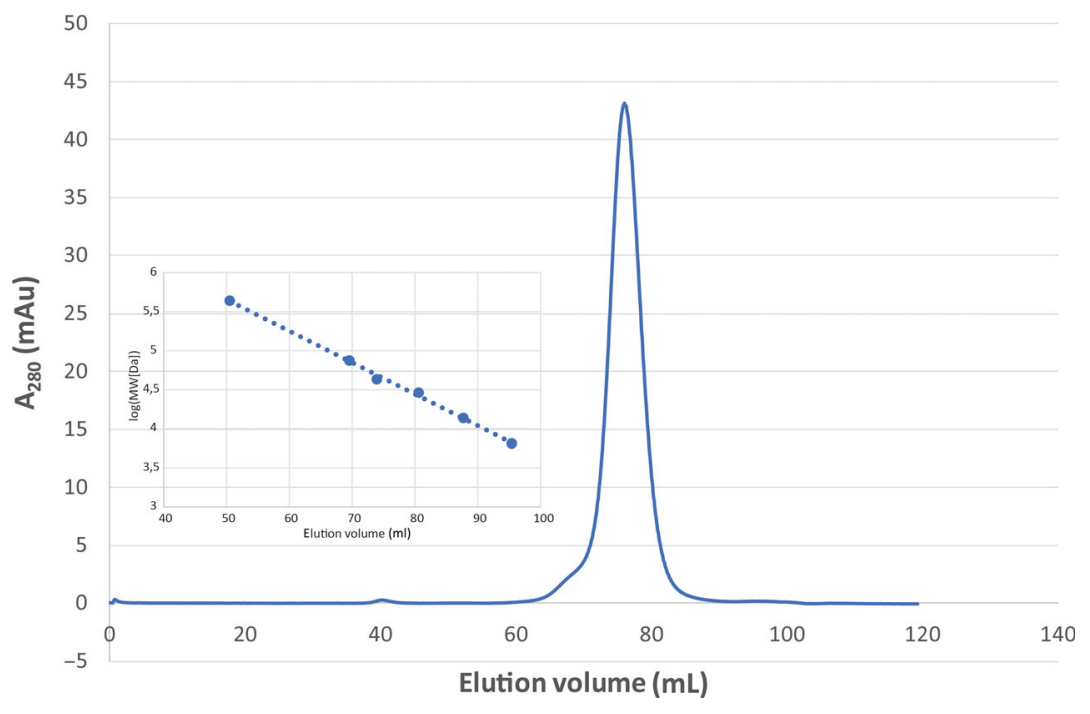

Fig. 2. Size-exclusion chromatography of MG Orn. The inset shows the calibration curve established with Ferritin (440 kDa), Conalbumin (75 kDa), Ovalbumin (43 kDa), Carbonic Anhydrase (29 kDa), RNase A (14 kDa), and Aprotinin (6.5 kDa). The $R^{2}$ value of the regression line is 0.997 . Based on the calibration curve and the elution volume, the estimated size of MG Orn is $41 \mathrm{kDa}$.
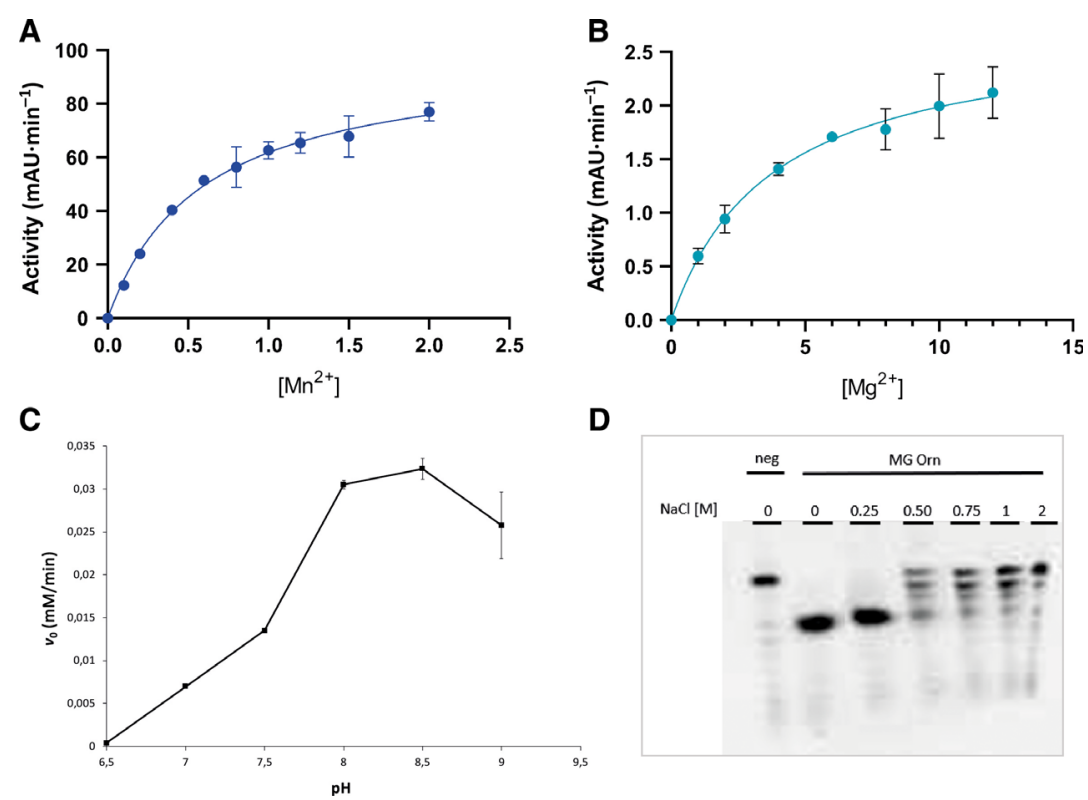

D

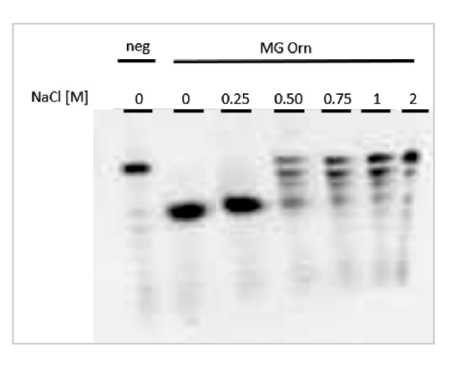

Fig. 3. Effect of $\mathrm{Mn}^{2+}(\mathrm{A})$ and $\mathrm{Mg}^{2+}(\mathrm{B}), \mathrm{pH}(\mathrm{C})$, and $\mathrm{NaCl}(\mathrm{D})$ on the nuclease activity of $\mathrm{MG}$ Orn. The effect of the metal ions and $\mathrm{pH}$ on the enzyme activity has been determined using the time-resolved pNP-TMP activity assay at $25{ }^{\circ} \mathrm{C}$ as described in Methods with $1.1 \mu \mathrm{g}$ Orn and varying amounts of $\mathrm{Mn}^{2+}$ and $\mathrm{Mg}^{2+}$ as well as $1.5 \mu \mathrm{g} \mathrm{MG}$ Orn and pH values from 6.5 to 9 using MES (pH 6.5), HEPES (pH 7-7.5), and Tris ( $\mathrm{pH}$ 8-9) as indicated in A-C. The rate of hydrolysis of pNP-TMP at the varying $\mathrm{pH}$ values was calculated according to Hamdan et al. [34]. Error bars indicate the standard deviation of the measurements. The effect of $\mathrm{NaCl}$ in a range of $0-2 \mathrm{M}$ is shown in (D) and has been tested at $25^{\circ} \mathrm{C}$ with the gel-based nuclease activity assay with $0.05 \mu \mathrm{m} 7 \mathrm{mer}$ RNA substrate and $0.8 \mu \mathrm{g} \mathrm{MG} \mathrm{Orn} \mathrm{in} 50 \mathrm{~mm}$ Tris- $\mathrm{HCl}$ $\mathrm{pH}$ 8.0, $0.2 \mathrm{mg} \cdot \mathrm{mL}^{-1}$ BSA, $2 \%$ glycerol and $1 \mathrm{~mm} \mathrm{MnCl}_{2}$ for $15 \mathrm{~min}$. Samples were analyzed on $20 \%$ denaturing PAA gels $(8 \times 8 \mathrm{~cm})$. Reaction buffer was used as negative control (Neg) instead of protein solution.

\section{Structural analysis}

The crystal structure of MG Orn was determined at $3.15 \AA$ resolution, by the molecular replacement method, using the oligoribonuclease from X. campestris (PDB: 2GBZ) as a template. A summary of the data collection, refinement, and validation statistics is given in Table 1. The crystal structure of MG Orn contains three monomers in the asymmetric unit. For all three chains, a continuous polypeptide comprising amino acid residues 5-181 (chains A and B) and 5-182 
Fig. 4. Temperature stability profile of MG Orn. The enzyme was preincubated at the respective temperature for $15 \mathrm{~min}$ and subsequently tested with the timeresolved $p$ NP-TMP assay at $25^{\circ} \mathrm{C}$ in $50 \mathrm{~mm}$ Tris $\mathrm{pH}$ 8.0, $200 \mathrm{~mm} \mathrm{NaCl}, 1 \mathrm{~mm}$ $\mathrm{MnCl}_{2}, 1.5 \mathrm{~mm}$ pNP-TMP, and $1.5 \mu \mathrm{g} \mathrm{MG}$ Orn. Activity measured of the sample preincubated at $4{ }^{\circ} \mathrm{C}$ was set as $100 \%$ residual activity. Error bars indicate the standard deviation of the measurements. The inset shows the graph determining the half-life of the enzyme at $50{ }^{\circ} \mathrm{C}$.

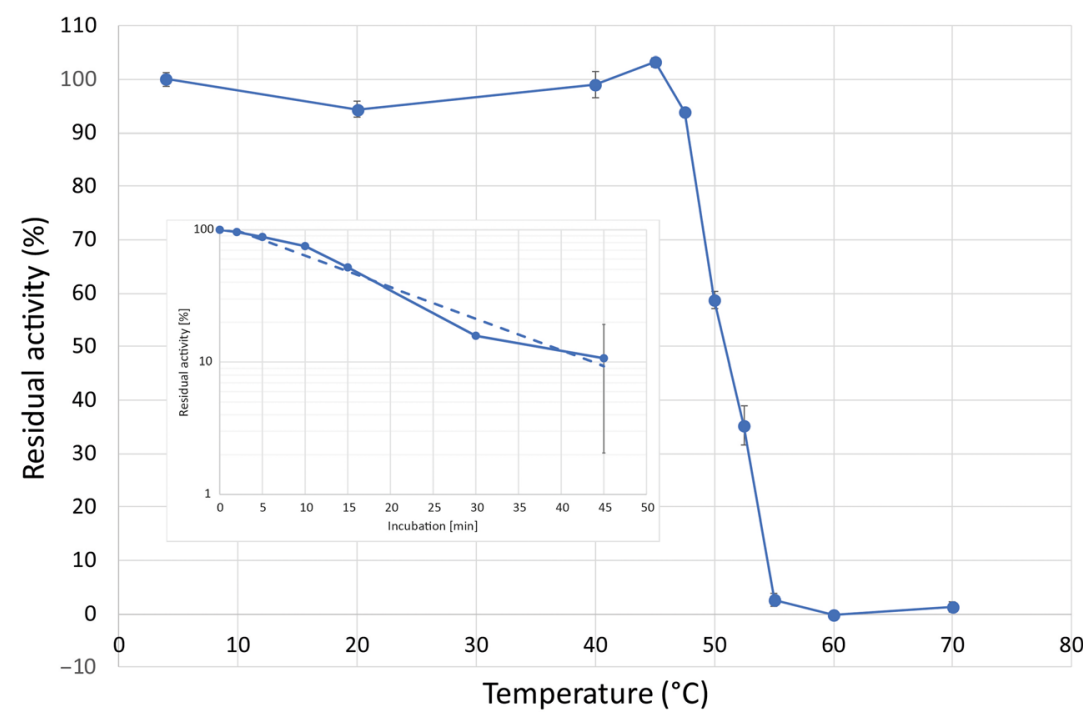

A
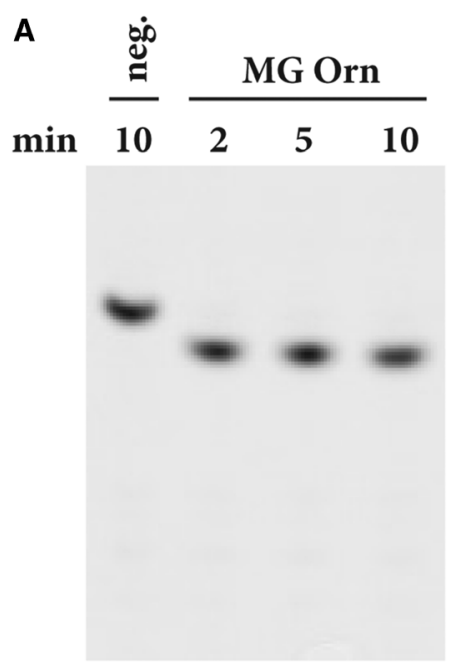

B

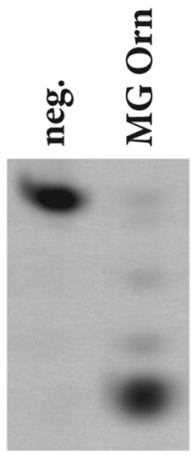

consists of nine $\alpha$-helices and five $\beta$-strands in the order $\quad \beta 1-\beta 2-\beta 3-\alpha 1-\alpha 2-\alpha 3-\alpha 4-\beta 4-\alpha 5-\alpha 6-\beta 5-\alpha 7-\alpha 8-\alpha 9$. The five-stranded $\beta$-sheet forms the core of the protein. It is aligned in the order $\beta 3-\beta 2-\beta 1-\beta 4-\beta 5$. Strand $\beta 2$ is antiparallel to the rest. The $\beta$-sheet is flanked by the $\alpha$-helices (Fig. 6A,B). Each monomer of MG Orn contains an $\mathrm{Mn}^{2+}$ ion in the active site, most probably resulting from buffers used for protein purification and storage of MG Orn. The metal ion is coordinated by Asp12, Glu14, both located on $\beta 1$, and Asp163, located on $\alpha 8$ (Fig. 6B, Fig. S1).

A surface representation clearly shows a cavity within the protein comprising of the amino acid residues forming the active site and known as the DEDDh motif, that is, Asp12, Glu14, Asp112, Asp163, and His158 (Figs S1 and S2).

The three-dimensional structure of MG Orn clearly indicates that monomer $\mathrm{A}$ and monomer $\mathrm{C}$ form a homodimer within the asymmetric unit, while monomer B forms a homodimer with a crystallographic copy of itself. The A-C homodimer is illustrated and focused on in the following discussion (Fig. 7A). The homodimers are connected through an intermolecular disulfide bond (representative electron density shown in Fig. S3). The dimer is further stabilized through salt bridges, H-bonds, and hydrophobic interactions. The active site of each monomer, including coordination of the $\mathrm{Mn}^{2+}$ ion, is still accessible and exposed to the solvent in the homodimer.

A structural analysis through PDBePISA [17] highlighted the disulfide bond (C:Cys110 - A:Cys110), two salt bridges (C:Arg130 [NH1] - A:Glu139 [OE1] and C:Glu139 [OE1] - A:Arg130 [NH1]), and a total of 17 $\mathrm{H}$-bonds as important contributors to the formation 
Table 1. Data collection, processing, and structure refinement statistics. Values in parentheses are for the outermost shell

\begin{tabular}{|c|c|}
\hline Diffraction source & BESSY II, BL 14.1 \\
\hline Wavelength $(\AA)$ & 0.91841 \\
\hline Temperature (K) & 100 \\
\hline Detector & PILATUS \\
\hline Crystal-to-detector distance (mm) & 647.31 \\
\hline Rotation range pr. image $\left({ }^{\circ}\right)$ & 0.1 \\
\hline Total rotation range $\left({ }^{\circ}\right)$ & 94 \\
\hline Space group & $P 3_{1} 21$ \\
\hline$a, b, c(\AA)$ & $108.32,108.32,101.33$ \\
\hline$\alpha, \beta, \gamma\left({ }^{\circ}\right)$ & $90,90,120$ \\
\hline Mosaicity $\left({ }^{\circ}\right)$ & 0.16 \\
\hline Resolution range $(\AA)$ & $42.57-3.15(3.37-3.15)$ \\
\hline Total no. of reflections & $63171(11289)$ \\
\hline No. of unique reflections & $12264(2200)$ \\
\hline Completeness (\%) & $99.9(100.0)$ \\
\hline Multiplicity & $5.2(5.1)$ \\
\hline$<I / \sigma(I)>$ & $8.2(1.6)$ \\
\hline$R_{\text {p.i.m. }}$ & $0.076(0.551)$ \\
\hline Overall $B$ factor from Wilson plot $\left(\AA^{2}\right)$ & 65.44 \\
\hline$\sigma$ cutoff & None \\
\hline Final $R_{\text {cryst }}$ & 0.2454 \\
\hline Final $R_{\text {free }}$ & 0.2655 \\
\hline Rotamer outliers (\%) & 5.34 \\
\hline Clashscore & 5.26 \\
\hline \multicolumn{2}{|l|}{ No. of non-H atoms } \\
\hline Protein & 4376 \\
\hline $\mathrm{Mn}$ & 3 \\
\hline Total & 4379 \\
\hline \multicolumn{2}{|l|}{ R.m.s. deviations } \\
\hline Bonds (Å) & 0.003 \\
\hline Angles $\left({ }^{\circ}\right)$ & 0.70 \\
\hline \multicolumn{2}{|l|}{ Average $B$ factors $\left(\AA^{2}\right)$} \\
\hline Overall & 82.53 \\
\hline Protein & 82.51 \\
\hline $\mathrm{Mn}$ & 103.38 \\
\hline \multicolumn{2}{|l|}{ Ramachandran plot (\%) } \\
\hline Preferred & 98.29 \\
\hline Allowed & 1.71 \\
\hline
\end{tabular}

of the stable homodimer. Furthermore, there are numerous hydrophobic interactions to stabilize the dimer interface, as a total of 20 amino acid residues from each monomer have more than $50 \%$ of their total area toward the interface. This accounts mainly to residues in the $\beta 5-\alpha 7$ region (MG Orn residues $130-$ 145) as well as both termini.

However, several Orn sequences do not contain a Cys residue but an Ala and Gly residue at position 110, respectively (Fig. S2). Table 2 displays putative interactions adding to the formation of the dimer for the different Orn macromolecules. Of the compared structures, MG Orn has the smallest buried surface area and number of hydrophobic contributors upon dimer formation, while differences in number of
$\mathrm{H}$-bonds and salt bridges are less pronounced. Interestingly, only some Orn proteins form an intermolecular disulfide bridge (Cys110-Cys110') crosslinking the monomers in the homodimer believed to be a major contributor to the overall stability of the homodimer. The effect of mutating the Cys residue in MG Orn was thus further investigated.

\section{Structural aspects of RNA substrate binding in MG Orn}

In order to investigate the structural basis for the observed in vitro processing of longer substrates (5mer, 7 mer, and 10mer RNA) shown for MG Orn, we used complexed E. coli exonuclease I (ExoI) as a model. ExoI is a three-domain protein, where the N-terminal domain has homology to the DnaQ superfamily. The crystal structure of ExoI in complex with ssDNA was superpositioned to the MG Orn structure (sequence identity of $13.2 \%$ for 151 aligned amino acid residues) with an r.m.s. deviation of $2.33 \AA$. The overlaid structure formed the template for manual fitting of a $5 \mathrm{mer}$ RNA molecule into the substrate binding cleft and active site of MG Orn. The modeled 5mer RNA molecule was visualized onto both the electrostatic potential and ConSurf molecular surfaces of the functional dimer of MG Orn (Fig. 7B,C). Nucleotides in the $5^{\prime}$ end of this model appear to be in tight interaction with a conserved sequence patch (His128'-Tyr129'Arg130') in the second monomer in the functional homodimer of MG Orn (Fig. 8). This sequence patch is most likely of importance for interaction with longer substrates.

\section{Role of the intermolecular disulfide bond for homodimer formation and nuclease function}

The importance of the intermolecular disulfide bond connecting two Orn monomers was demonstrated by comparing the biochemical properties of MG Orn and the two variants OrnC110G and OrnC110A. Following the same procedure as for MG Orn production, OrnC110A and OrnC110G were recombinantly produced in E. coli and purified to homogeneity (Fig. S4).

Thermal stability of MG Orn, OrnC110A, and OrnC110G was evaluated by ThermoFluor assay, monitoring changes in hydrophobic fluorescent dye binding upon protein unfolding. All proteins followed the expected shapes of a thermal denaturation profile, displaying an observable melting transition between folded and unfolded states. MG Orn showed a broader thermal unfolding profile compared to the narrower profile of OrnC110A and OrnC110G, possibly 
Fig. 6. Topology diagram and monomeric structure of MG Orn. (A) Topology diagram displaying the order of the secondary structure elements. (B) Cartoon representation of a monomer of MG Orn. In both figures, the $\mathrm{N}$ and $\mathrm{C}$ termini are indicated, and secondary structure elements are colored in rainbow colors ranging from blue to red. The bound $\mathrm{Mn}^{2+}$ ion is shown as purple sphere.
A

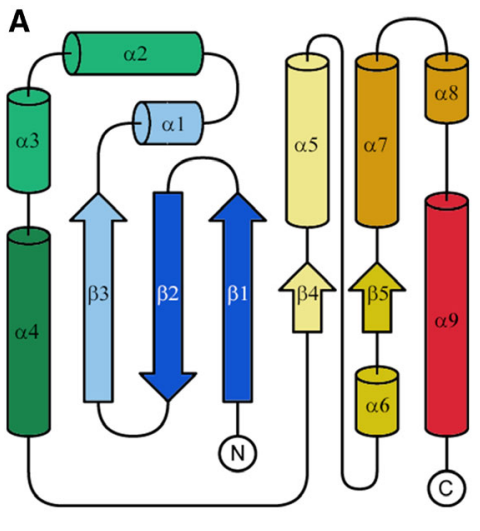

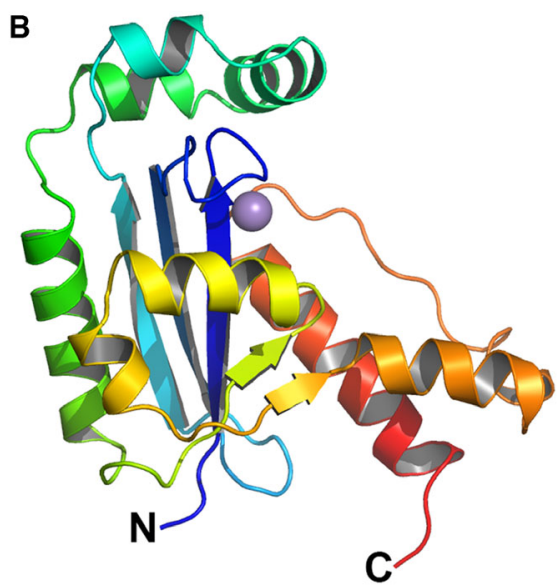

reflecting two transitions of the dimeric MG Orn (Fig. S4). The calculated melting temperature $\left(T_{\mathrm{m}}\right)$ for the three enzyme variants was similar being $55^{\circ} \mathrm{C}$ for MG Orn and $55.6{ }^{\circ} \mathrm{C}$ and $54.7^{\circ} \mathrm{C}$ for OrnC110A and OrnC110G, respectively (Fig. S4).

Two different assay setups were used to investigate the effect of mutating the intermolecular disulfide bridge in the homodimer. The first assay was monitoring the nuclease activity using $p$ NP-TMP, a dinucleotide mimic of a natural nucleic acid, as substrate. The C110G mutation abolished approximately $80 \%$ of enzymatic activity on $p$ NP-TMP, compared to MG Orn, whereas the $\mathrm{C} 110 \mathrm{~A}$ mutation almost completely inactivated the enzyme (Fig. 9).

The second assay employed utilized RNA molecules of different length as substrate. While MG Orn displayed a robust exoribonuclease activity on both $7 \mathrm{mer}$ and 10mer RNA, OrnC110A showed complete loss of activity on these RNA substrates. The degradation pattern indicates that OrnC110G may have a miniscule capacity to act on both $7 \mathrm{mer}$ and 10mer (Fig. 10). Similar results were obtained by increasing the reaction temperature to $37^{\circ} \mathrm{C}$ (Fig. S5).

In order to investigate the role of the disulfide bridge after forming the functional dimer, we added increasing amount of the reducing agent DTT to MG Orn at three different temperatures (Fig. 11A,B). MG Orn showed activity in the presence of up to $10 \mathrm{~mm}$ DTT at $25^{\circ} \mathrm{C}$ and $37^{\circ} \mathrm{C}$. Partial inhibition of activity could be detected only in the presence of $10 \mathrm{~mm}$ DTT at $45{ }^{\circ} \mathrm{C}$.

\section{Discussion}

Phylogenetic analysis of the Svalbard metagenome Orn (MG Orn) described here strongly indicates that MG Orn originates from a species within the Arenicellales order, possibly Arenicellas or another close relative
Ar. xantha. Although the dataset is limited (175 residues), the close relation of MG Orn to Ar. xantha Orn and its identification as a gammaproteobacterium is strongly supported by this result.

MG Orn is shown to exist as a dimer in solution in correspondence with other described Orn enzymes such as E. coli Orn $[12,13]$. It has a $3^{\prime}-5^{\prime}$ directionality and rapidly degrades small oligoribonucleotides to monoribonucleotides. $\mathrm{MG}$ Orn prefers $\mathrm{Mn}^{2+}$ over $\mathrm{Mg}^{2+}$ as divalent cation at $\mathrm{pH} 8.5$ for optimal nuclease activity and possesses a quite broad salt tolerance. This broad salt tolerance, with maximum approximately between 250 and $500 \mathrm{~mm} \mathrm{NaCl}$ and detectable activity up to $2 \mathrm{~m}$, may arise due to its marine origin and the variable salt tolerance in the littoral zone [18]. As expected, originating from a cold marine habitat MG Orn shows significantly lower thermal stability compared to its mesophilic E. coli counterpart. MG Orn showed a $t_{1 / 2}$ of $15 \mathrm{~min}$ at $50{ }^{\circ} \mathrm{C}$, while E. coli Orn previously has been shown to still retain $50 \%$ residual activity after $60 \mathrm{~min}$ at $65^{\circ} \mathrm{C}$ [11].

The three-dimensional structure of MG Orn indicates that it functions as a homodimer, where two monomers are connected to each other through an intermolecular disulfide bond (Fig. S3). In addition, several other interactions also contribute to the dimerization interface including hydrophobic interactions, salt bridges, and $\mathrm{H}$-bonds.

In this study, we wanted to investigate the functional role of the intermolecular disulfide bridge (Cys110-Cys110') connecting the two monomers, and mutated Cys 110 to Gly and Ala, amino acid residues naturally occurring at the respective position in other deposited Orn structures. The thermal stability of MG Orn, OrnC110A, and OrnC110G was investigated using a ThermoFluor assay. The ThermoFluor data show a broader thermal unfolding profile for MG Orn 
A
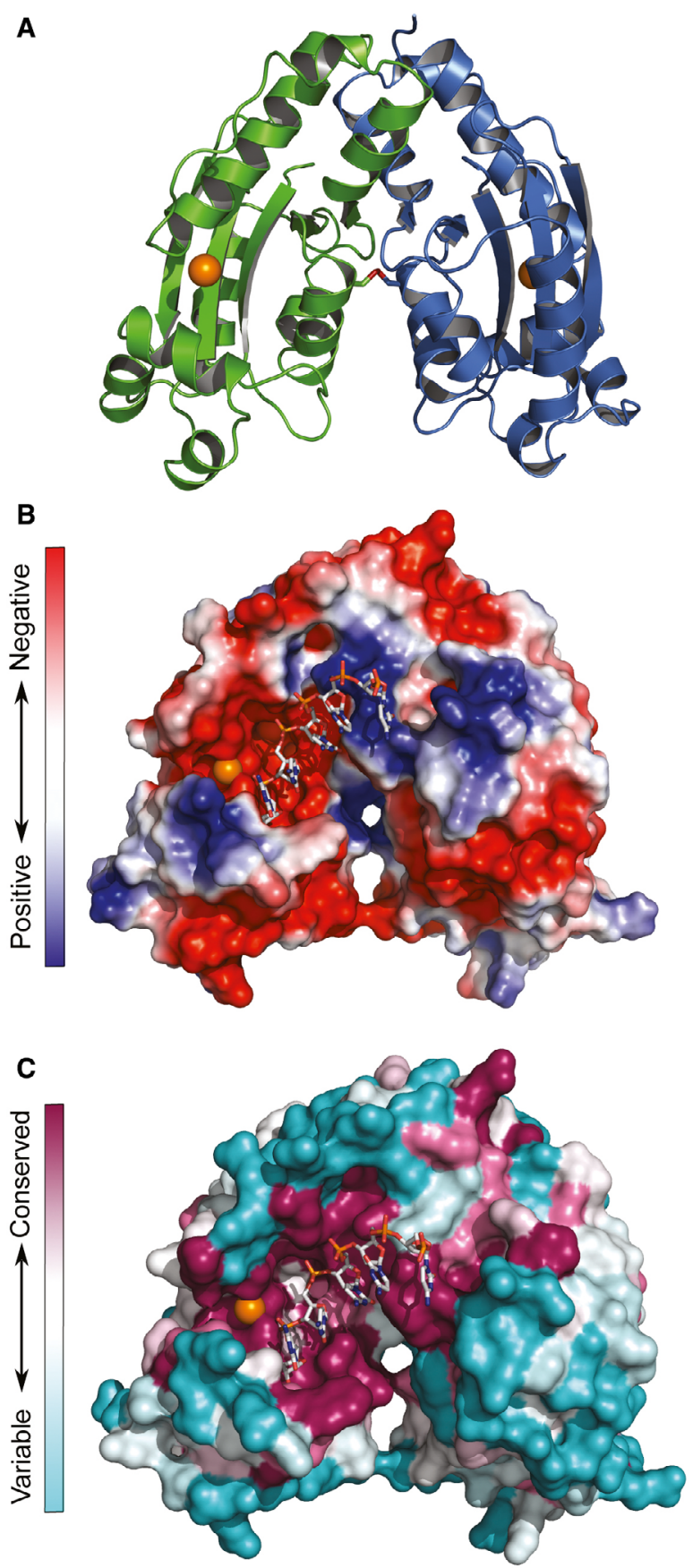

Fig. 7. The functional dimer of MG Orn. (A) Cartoon representation of the functional dimer of MG Orn with the two monomers colored individually. The $\mathrm{Mn}^{2+}$ ion is indicated as an orange sphere, and the intermolecular disulfide bond is shown as sticks with sulfur atoms colored orange. (B) Electrostatic potential mapped onto the molecular surface of the MG Orn dimer. The colors range from red (negative potential) to blue (positive potential). (C) Sequence conservation from the ConSurf analysis mapped onto the molecular surface of the MG Orn dimer. The colors range from deep purple (conserved residues) to mint (variable residues). In $\mathrm{B}$ and $\mathrm{C}$, the modeled 5mer RNA is shown as a stick model. compared to OrnC110A and OrnC110G, possibly reflecting two transitions of the dimeric MG Orn. This broader profile is probably due to dissociation of the dimer ahead of monomer unfolding. Dimer disruption allows access of the fluorescence dye to the revealed hydrophobic areas of the interface, leading to an earlier increase in the recorded fluorescence intensity. Thus, the thermal unfolding temperature of MG Orn and its variants is around $55^{\circ} \mathrm{C}$, indicating that mutation of the cysteine involved in dimer formation does not influence the thermal stability of Orn.

Using the dinucleotide substrate mimic $p$ NP-TMP, as well as oligoribonucleotides of different lengths, we could show that the mutations severely affected MG Orn's ability to act as an exoribonuclease. These results indicate that residue $\mathrm{C} 110$ and its intermolecular disulfide bond are essential for homodimer formation and catalytic function of MG Orn. However, other interactions must also be important for maintaining the dimer formation once it is formed and was further proven by adding the reducing agent DTT to MG Orn. MG Orn showed surprising resilience toward DTT, and inhibition of exoribonuclease activity could only be detected using $10 \mathrm{~mm}$ DTT at $45^{\circ} \mathrm{C}$.

Coordination of the $\mathrm{Mn}^{2+}$ ion by Asp12 and Glu14, located on $\beta 1$, and Asp163, located on $\alpha 8$, is also seen by the corresponding amino acid residues in Cox. burnetii Orn (PDB code 3TR8). X. campestris Orn and Colwellia psychrerythraea Orn (PDB code $2 \mathrm{GBZ}$ and $6 \mathrm{~A} 4 \mathrm{~A}$, respectively), on the other hand, each contain one $\mathrm{Mg}^{2+}$ ion. The site for binding of $\mathrm{Mg}^{2+}$ differs slightly from the binding site for $\mathrm{Mn}^{2+}$. However, in both protein structures the $\mathrm{Mg}^{2+}$ ion is coordinated by Asp12 and Glu14 as is the $\mathrm{Mn}^{2+}$ in MG Orn and Cox. burnetii Orn. Whereas Glu14 shows the same orientation in all four proteins, the orientation of Asp12 depends on the nature of the metal-ion bound that is tilted by $35^{\circ}$. Binding of $\mathrm{Mg}^{2+}$ in $X$. campestris Orn and Col. psychrerythraea Orn is further supported by Asp112, residing on $\alpha 5$. The respective Asp residue in MG Orn and Cox. burnetii Orn is not involved in binding of the $\mathrm{Mn}^{2+}$ ion. Asp112, involved in $\mathrm{Mn}^{2+}$ binding as mentioned above, is also involved in $\mathrm{Mg}^{2+}$ binding in Col. psychrerythraea. Compared to Asp163 in MG Orn, this Asp residue is tilted toward the metal ion by $\sim 40^{\circ}$.

Lately, a paper describing binding of U-U and $p$ NPTMP has been published [16]. In our study, we have shown that MG Orn efficiently acts on the dinucleotide analogue $p$ NP-TMP as well as on 5mer, 7mer, and 10mer RNA substrates. In order to explain the structural basis for the observed in vitro processing of 'longer' oligoribonucleotides shown for MG Orn, complexed E. coli exonuclease I (ExoI) was used as a 
Table 2. Interface analysis of the MG Orn homodimer and its homologues. Performed with PDBePISA [17]

\begin{tabular}{|c|c|c|c|c|c|c|c|}
\hline Orn & $\begin{array}{l}\text { PDB } \\
\text { code }\end{array}$ & $\begin{array}{l}\text { Buried } \\
\text { area, } \AA^{2}\end{array}$ & $\begin{array}{l}\text { aa residue } \\
\text { at position } 110\end{array}$ & $\begin{array}{l}\text { Number of } \\
\text { disulfide bridges }\end{array}$ & $\begin{array}{l}\text { Number of } \\
\text { H-bonds }\end{array}$ & $\begin{array}{l}\text { Number of } \\
\text { salt bridges }\end{array}$ & $\begin{array}{l}\text { Number of hydrophobic } \\
\text { contributors }^{a}\end{array}$ \\
\hline MG Orn & $6 \mathrm{RK} 6$ & 1402.1 & Cys & 1 & 17 & 2 & 20 \\
\hline Xanthomonas campestris Orn & $2 \mathrm{GBZ}$ & 1753.7 & Cys & 1 & 19 & 4 & 28 \\
\hline Coxiella burnetii Orn & 3TR8 & 1622.8 & Cys & 1 & 19 & 1 & 29 \\
\hline Acinetobacter baumannii Orn & $5 \mathrm{CY} 4$ & 1602.0 & Cys & 1 & 18 & 6 & 24 \\
\hline Haemophilus influenzae Orn & $1 \mathrm{~J} 9 \mathrm{~A}$ & 1638.4 & Ala & 0 & 21 & 4 & 27 \\
\hline Escherichia coli Orn & $2|G|$ & 1608.5 & Gly & 0 & 17 & 2 & 28 \\
\hline Colwellia psychrerythraea Orn & $6 \mathrm{~A} 4 \mathrm{~A}$ & 1516.9 & Gly & 0 & 14 & 4 & 27 \\
\hline
\end{tabular}

${ }^{a}$ Hydrophobic residues with more than $50 \%$ of their total area toward the interface according to PDBePISA.

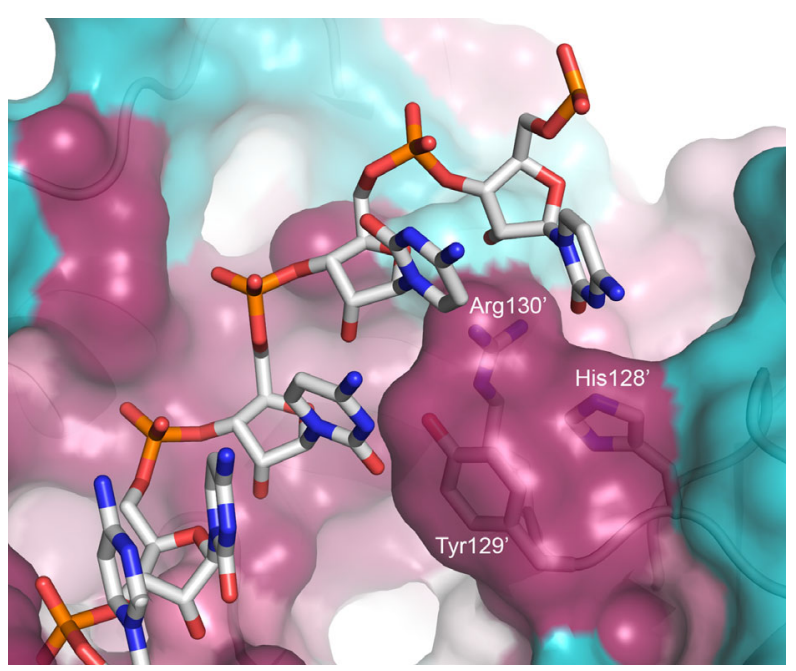

Fig. 8. The $5^{\prime}$ end of the modeled 5 mer RNA molecule is in proximity to the conserved sequence patch His128', Tyr129', and Arg130' in the neighboring monomer. The surface is colored based on the ConSurf output with colors ranging from deep purple (conserved residues) to mint (variable residues).

template for manual docking of 5mer RNA into the binding pocket. Although the sequence identity between MG Orn and ExoI is low, the structure-based alignment revealed interesting conservation in the active-site region. Notably, except for His158 (which appears to be in a somewhat flipped-out state in the MG Orn structure), all amino acid residues in the signature DEDDh cluster were structurally conserved between the two structures.

The coordination of the $3^{\prime}$ end of the nucleotide substrate (ssDNA in ExoI; RNA in MG Orn) into the respective active sites is at overlapping positions in $\mathrm{MG}$ Orn compared to ExoI. There is a marked difference in polarity between ExoI and MG Orn in the region around the $2^{\prime}$-position of the $3^{\prime}$-sugar unit of the oligonucleotide. Where this area is relatively spacious and nonpolar in ExoI, corresponding to the nature of the deoxyribose in an ssDNA substrate, it is instead rather polar in MG Orn (Thr and Ala in ExoI are replaced with His and Asn in MG Orn). A loop region (His128', Tyr129', and Arg130') from the neighboring monomer in the functional dimer is in proximity to the $5^{\prime}$ region of the modeled RNA molecule. Tyr129' and Arg130' have very recently been implicated as important for binding and processing of dinucleotides. When Tyr129' was exchanged to Ala in Col. psychrerythraea Orn, no significant change in hydrolytic activity against $p$ NP-TMP was observed, thus indicating that Tyr129' does not play a vital role in processing of dinucleotide substrates [16]. However, based on modeling of $\mathrm{MG}$ Orn with a 5 mer RNA, there are clear indications that these residues indeed play an important role in stabilizing the RNA substrate when MG Orn is processing RNA molecules longer than dinucleotides. The importance of these residues is further supported by the fact that the residues in this loop are completely conserved among 150 Orn homologues.

\section{Conclusion}

This study highlights the importance of dimer formation for substrate binding and subsequent catalytic action in MG Orn. We show an important role of an intermolecular disulfide bond for the formation of the homodimer, which proves to be essential for the ability of the enzyme to degrade small oligoribonucleotides. We also show the in vitro ability of MG Orn to act on 'longer' RNA oligos (5-10mer), probably through the involvement of a conserved sequence loop (His128', Tyr129' and Arg130') in the neighboring monomer when binding longer RNA substrates.

\section{Methods}

\section{Bioinformatics}

A maximum likelihood (ML) phylogeny (JTT model) was constructed based on a dataset containing nine Orn 


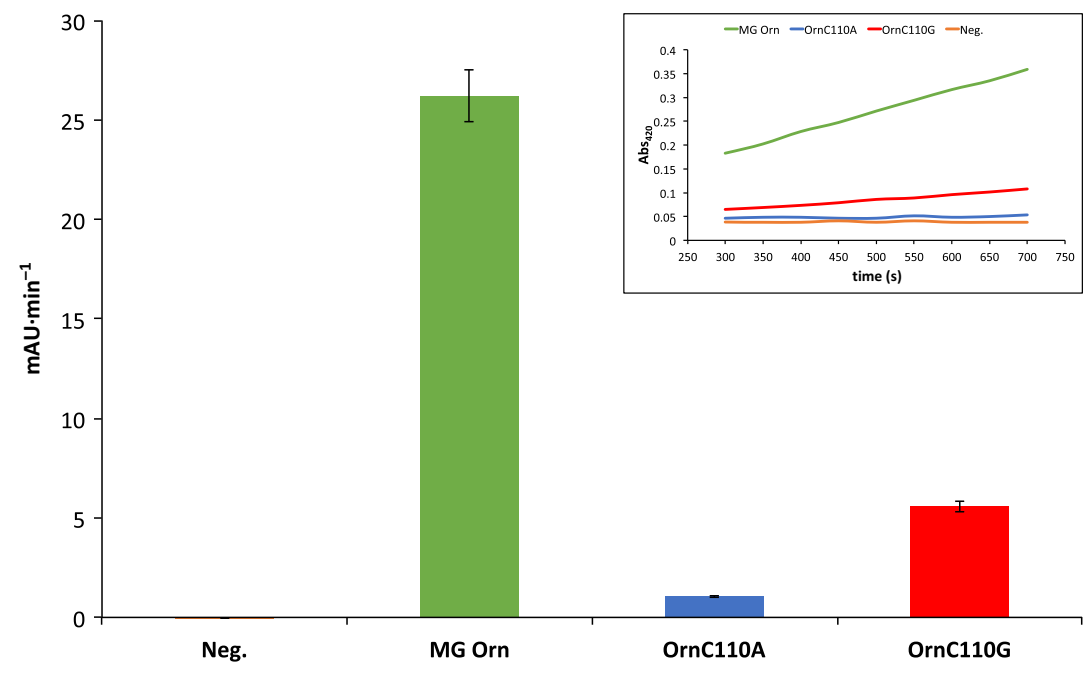

Fig. 9. Enzymatic activity of MG Orn (green), OrnC110A (blue), and OrnC110G (red). RNA degradation was tested with the time-resolved $p N P-T M P$ activity assay with $1.5 \mathrm{~mm}$ pNP-TMP and $2 \mu \mathrm{g}$ Orn in $50 \mathrm{~mm}$ Tris pH 8, $200 \mathrm{~mm} \mathrm{NaCl}, 1 \mathrm{~mm}$ $\mathrm{MnCl}_{2}$ at $25^{\circ} \mathrm{C}$. The graph shows the increase in absorbance over time for $\mathrm{MG}$ Orn, its mutants, and the negative control (Neg.). The calculated error bars denote the standard deviation between duplicate runs. The inset shows the absorbance $\left(\mathrm{Abs}_{420}\right)$ of the reaction product plotted against the time for each enzymatic reaction. 7mer RNA

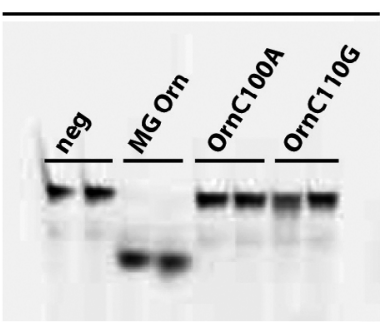

Fig. 10. Nuclease activity of $M G$ Orn and variants on 7mer and 10mer RNA substrates. RNA degradation was investigated using the gel-based nuclease activity assay with $25 \mathrm{~nm}$ substrate and $0.8 \mu \mathrm{g}$ enzyme in $50 \mathrm{~mm}$ Tris $\mathrm{pH} 8.0,200 \mathrm{~mm} \mathrm{NaCl}, 0.2 \mathrm{mg} \cdot \mathrm{mL}^{-1}$ BSA, $2 \%$ glycerol, and $1 \mathrm{~mm} \mathrm{MnCl}_{2}$ for $15 \mathrm{~min}$ at $25{ }^{\circ} \mathrm{C}$. Samples were analyzed on $20 \%$ denaturing PAA gels $(8 \times 8 \mathrm{~cm})$. Reaction buffer replaced protein solution in the negative control (Neg).

sequences, seven from gammaproteobacteria and two from betaproteobacteria (used as outgroup), using the MEGA $\mathrm{x}$ software $[19,20]$. A bootstrap analysis was done to test the stability of nodes, using the ML method and JTT model, with 500 pseudoreplicates [19]. The protein alignment included sequences from Ar. xantha WP_113955167.1, X. campestris WP_011037314.1, P. aeruginosa RQB22498.1, Cox. burnetii WP_005770781.1, Ac. baumannii SST03775.1, H. influenzae WP_021035403.1, E. coli WP_042004351.1, Bordetella trematum WP_025512385.1, and Achromobacter piechaudii WP_006218241.1. Alignment files were generated using CLUSTALW [21].

\section{Cloning of the gene encoding MG Orn}

The $m g$ orn gene (Fig. S6) has been cloned into the $\mathrm{pENTR}^{\mathrm{TM}} /$ TEV/D-TOPO ${ }^{\mathrm{TM}}$ entry vector by Directional TOPO ${ }^{\circledR}$ Cloning from Thermo Fisher Scientific (Waltham, MA, USA) (forward primer: 5'-CACC GTG CCG CAA AAC CCA AAT GTT-3', reverse primer: 5' - TTA GTT CAT ATC GAG CAG TAT CAG ATT GTT TCG-3'). Positive clones have been confirmed by sequencing analysis. The gene has been subsequently transferred into the destination vector pHMGWA by the LR Clonase reaction using Gateway ${ }^{\mathrm{TM}}$ LR Clonase $^{\mathrm{TM}}$ II Enzyme Mix (Thermo Fisher Scientific). Positive clones have been confirmed by sequencing analysis. Due to the cloning procedure applied, the $m g$ orn gene could be expressed with an N-terminal $\mathrm{His}_{6}$-MBP-tag followed by a recognition sequence for the TEV protease (TEV protease).

\section{Preparation of mutant constructs}

Substitution of Cys110 by Ala and Gly, respectively, was performed using the QuikChange II Site-Directed Mutagenesis Kit (Agilent Technologies, Santa Clara, CA, USA). The pHMGWA plasmid containing mg orn was used as a template for single substitutions with synthetic oligonucleotide primers (OrnC110A: forward primer: 5'-GCG GTA ATA GCA TTG CGC AAG ATC GCC G-3', reverse primer: 5'CGG CGA TCT TGC GCA ATG CTA TTA CCG C-3'; OrnC110G: forward primer: 5'-GCG GTA ATA GCA TTG GCC AAG ATC GCC G-3', reverse primer: 5'-CGG CGA TCT TGG CCA ATG CTA TTA CCG C-3'). Both mutations were confirmed by sequencing analysis.

\section{Recombinant expression}

For recombinant expression of $m g$ orn with an N-terminal His $_{6}$-MBP-tag, the plasmid has been transformed into Rosetta 2 (DE3) cells (Merck KGaA, Darmstadt, Germany). Several colonies were picked and incubated in $50 \mathrm{~mL}$ LB media containing $100 \mu \mathrm{g} \cdot \mathrm{mL}^{-1}$ ampicillin at $37^{\circ} \mathrm{C}, 225$ r.p.m., overnight. One liter of $\mathrm{LB} /$ ampicillin $\left(100 \mu \mathrm{g} \cdot \mathrm{mL}^{-1}\right)$ medium was inoculated with $20 \mathrm{~mL}$ of overnight culture and grown at 


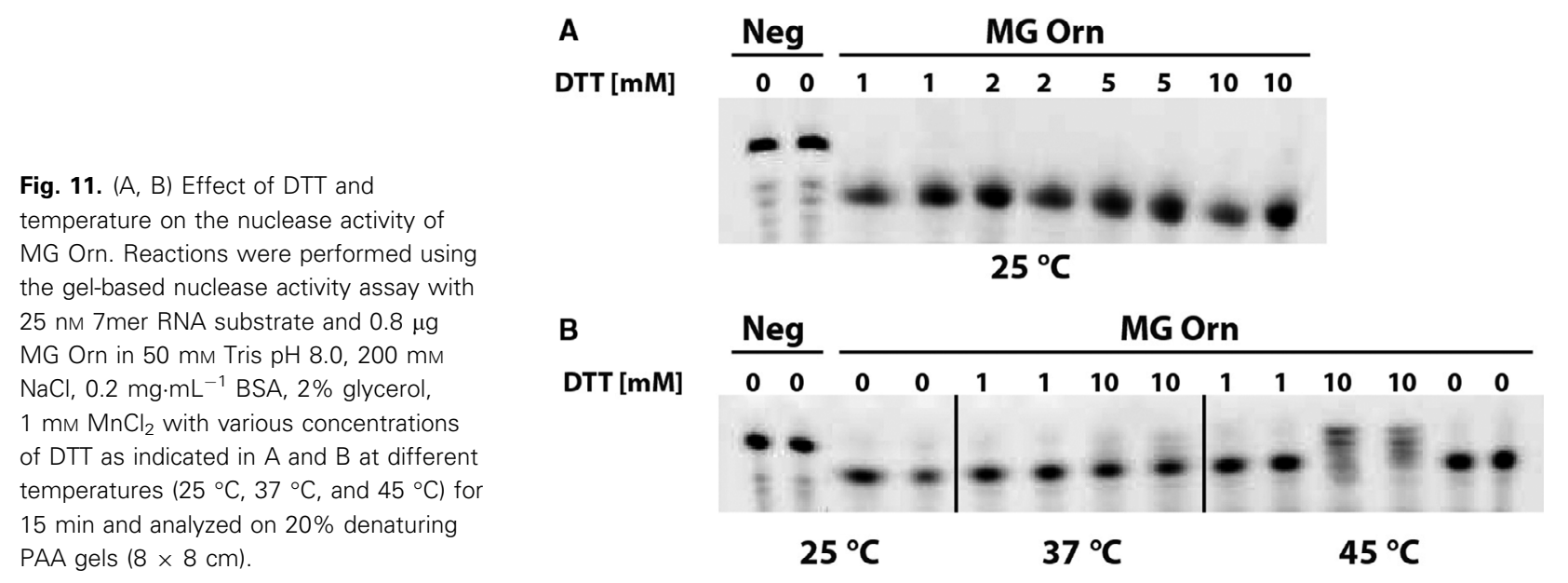

$37^{\circ} \mathrm{C}, 180$ r.p.m., until cell density reached $\mathrm{OD}_{600}$ of 0.5 . Gene expression was induced by addition of $0.5 \mathrm{~mm}$ IPTG, and protein production was carried out for $4 \mathrm{~h}$ at $20^{\circ} \mathrm{C}$ and 180 r.p.m.

\section{Protein purification of MG Orn, OrnC110A, and OrnC110G}

Cell lysis and all purification steps were carried out at $4{ }^{\circ} \mathrm{C}$. Cell pellets from a $1-\mathrm{L}$ cultivation were resuspended in $30 \mathrm{~mL}$ lysis buffer $\left[50 \mathrm{~mm}\right.$ Tris $\mathrm{pH} 7.4$ (at $25^{\circ} \mathrm{C}$ ), $300 \mathrm{~mm} \mathrm{NaCl}, 1 \mathrm{~mm} \mathrm{MnCl}_{2}$ ], one protease inhibitor tablet (cOmplete $^{\mathrm{TM}}$, Mini, EDTA-free Protease Inhibitor Cocktail; Roche, Basel, Switzerland), and $10 \mu \mathrm{g} \cdot \mathrm{mL}^{-1}$ lysozyme. After incubation on ice for $30 \mathrm{~min}$, cell lysis was performed by sonication with the VCX 750 from Sonics ${ }^{\circledR}$ (Newtown, CT, USA) (pulse 1.0/1.0, $20 \mathrm{~min}$, amplitude 25\%). Insoluble cell debris was removed by centrifugation (48 $384 \mathrm{~g}$, $45 \mathrm{~min}, 4^{\circ} \mathrm{C}$ ). The supernatant was filtered through a $0.45-$ $\mu \mathrm{M}$ membrane and loaded onto a 1-mL HisTrap ${ }^{\mathrm{TM}}$ HP column (GE Healthcare, Wood Dale, IL, USA) in buffer A [50 mM Tris pH 7.4 (at $25^{\circ} \mathrm{C}$ ), $300 \mathrm{~mm} \mathrm{NaCl}, 1 \mathrm{~mm}$ $\mathrm{MnCl}_{2}$ ] and washed in three steps: (a) buffer A2 [50 mM Tris pH 7.4 (at $25^{\circ} \mathrm{C}$ ), $1 \mathrm{M} \mathrm{NaCl}, 1 \mathrm{mM} \mathrm{MnCl}_{2}$ ], (b) buffer A, and (c) $5 \%$ buffer B [50 mM Tris pH 7.4 (at $25^{\circ} \mathrm{C}$ ), $300 \mathrm{~mm} \mathrm{NaCl}, 1 \mathrm{~mm} \mathrm{MnCl}_{2}, 500 \mathrm{~mm}$ imidazole]. His $6^{-}$ MBP-tagged protein was eluted on a $20 \mathrm{~mL}$ gradient from $5 \%$ to $100 \%$ buffer B. Fractions containing the protein were exchanged into buffer A by using a 5-mL HiTrap ${ }^{\mathrm{TM}}$ Desalting column (GE Healthcare). TEV protease cleavage was performed overnight with $0.1 \mathrm{mg}$ TEV per $1 \mathrm{~mL}$ of eluted fusion protein in $50 \mathrm{~mm}$ Tris $\mathrm{pH} 8.0$ (at $25^{\circ} \mathrm{C}$ ), $0.5 \mathrm{~mm}$ EDTA, and $1 \mathrm{~mm}$ DTT at $4{ }^{\circ} \mathrm{C}$ (TEV protease produced in-house). Protease-treated protein was separated from remaining impurities and the $\mathrm{His}_{6}$-MBP-tag by reverse affinity chromatography on a $1-\mathrm{mL} \operatorname{HisTrap}^{\mathrm{TM}} \mathrm{HP}$ column with buffer A. Fractions from flow-through and the initial phase of the first gradient at $5 \%$ buffer $\mathrm{B}$ were collected, added to an equal amount of buffer A, and loaded

onto a $1 \mathrm{~mL}$ HiTrap ${ }^{\mathrm{TM}}$ Blue HP column (GE Healthcare) in buffer A3 [50 mm HEPES pH 7.4 (at $25^{\circ} \mathrm{C}$ ), $50 \mathrm{~mm} \mathrm{NaCl}$, $1 \mathrm{~mm} \mathrm{MnCl}_{2}$ ]. The protein was eluted using $100 \%$ buffer B2 [50 mм HEPES pH 7.4 (at $25^{\circ} \mathrm{C}$ ), $2 \mathrm{M} \mathrm{NaCl}, 1 \mathrm{~mm} \mathrm{MnCl}_{2}$ ], and eluted peak fractions were analyzed by SDS/PAGE. Fractions containing the protein were exchanged into buffer C [20 mm HEPES pH 7.4 (at $25^{\circ} \mathrm{C}$ ), $150 \mathrm{~mm} \mathrm{NaCl}, 1 \mathrm{~mm}$ $\mathrm{MnCl}_{2}$ ], up-concentrated to approximately $1 \mathrm{mg} \cdot \mathrm{mL}^{-1} \mathrm{using}$ Amicon Ultra centrifugal filter units (MWCO $10 \mathrm{kDa}$, Merck KGaA), and stored at $-20{ }^{\circ} \mathrm{C}$ for activity and stability assays with $50 \%(\mathrm{v} / \mathrm{v})$ glycerol.

\section{Size-exclusion chromatography}

For crystallization trials and characterization of MG Orn stoichiometry, size-exclusion chromatography was performed. Up-concentrated Orn eluted from the HiTrap ${ }^{\mathrm{TM}}$ Blue HP column was run on a HiLoad ${ }^{\circledR} 16 / 600$ Superdex $^{\circledR} 200$ pg column (GE Healthcare) at $1 \mathrm{~mL} \cdot \mathrm{min}^{-1}$ with $20 \mathrm{~mm}$ HEPES pH 7.5 (at $25^{\circ} \mathrm{C}$ ), $150 \mathrm{~mm} \mathrm{NaCl}, 1 \mathrm{~mm} \mathrm{MnCl}_{2}$. Fractions containing $\mathrm{MG}$ Orn were collected and concentrated up to $3.6 \mathrm{mg} \cdot \mathrm{mL}^{-1}$ for crystallization trials. For molecular weight determination, and thus stoichiometry, standard proteins [Ferritin (440 kDa), Conalbumin (75 kDa), Ovalbumin (43 kDa), Carbonic Anhydrase (29 kDa), RNase A $(14 \mathrm{kDa})$, and Aprotinin $(6.5 \mathrm{kDa})]$ have been applied onto the HiLoad ${ }^{\circledR} 16 / 600$ Superdex ${ }^{\circledR} 200$ pg column (GE Healthcare) at the same flow rate and buffer as mentioned for MG Orn. The known molecular weight and the elution volume of the individual proteins have been used to draw up a calibration curve. Based on this calibration curve and its elution volume, the molecular weight for the MG Orn macromolecule in solution has been calculated.

\section{ThermoFluor assay}

The melting temperature $\left(T_{\mathrm{m}}\right)$ of $\mathrm{Mg}$ Orn, OrnC110A, and OrnC110G, thus the thermal stability of the proteins, was determined by ThermoFluor experiments according to Ref. 
[22]. The reactions contained $50 \mathrm{~mm}$ HEPES $\mathrm{pH} 7.5$ (at $\left.25^{\circ} \mathrm{C}\right), 72 \mathrm{~mm} \mathrm{NaCl}, \mathrm{SYPRO}^{\circledR}$ Orange (Merck KGaA) in a final dilution of $6 \times$ and $4 \mu \mathrm{g}$ of protein. All components were mixed thoroughly in a well of a thin-wall PCR plate (Bio-Rad, Hercules, CA, USA). The wells were sealed with optical-quality sealing tape (Bio-Rad). The volume of the final reaction was $25 \mu \mathrm{L}$. A temperature range of $10-90{ }^{\circ} \mathrm{C}$ with an increment of $0.3{ }^{\circ} \mathrm{C}$ at 3 -s intervals has been scanned in the ThermoFluor experiment (excitation at $495 \mathrm{~nm}$, emission at $556 \mathrm{~nm}$ ).

\section{Protein crystallization and $\mathrm{X}$-ray data collection}

Crystallization experiments were performed with a stock solution of purified MG Orn at $3.6 \mathrm{mg} \cdot \mathrm{mL}^{-1}$ in $20 \mathrm{~mm}$ HEPES pH 7.5 (at $25^{\circ} \mathrm{C}$ ), $150 \mathrm{~mm} \mathrm{NaCl}, 1 \mathrm{~mm} \mathrm{MnCl}_{2}$. Initial crystallization conditions were screened using the vapor diffusion method set up by a Phoenix crystallization robot (Art Robbins Instruments, Sunnyvale, CA, USA). The plates were set up with $60 \mu \mathrm{L}$ reservoir solution and sitting drops with equal amounts of reservoir solution mixed with protein stock solution in a total drop volume of $0.5 \mu \mathrm{L}$. The screens were incubated at $4{ }^{\circ} \mathrm{C}$. Diffractionquality crystals were found after 2 weeks at a condition containing $0.1 \mathrm{M}$ HEPES $\mathrm{pH} 7$ (at $25^{\circ} \mathrm{C}$ ) and $5 \%$ PEG 8000. Crystals were harvested, transferred through a cryoprotectant solution consisting of the reservoir solution with $30 \%(\mathrm{v} / \mathrm{v})$ glycerol added, and flash-cooled in liquid $\mathrm{N}_{2}$. X-ray diffraction data were collected at BL14.1 operated by the Helmholtz-Zentrum Berlin (HZB) at the BESSY II electron-storage ring (Berlin-Adlershof, Germany; Ref.[23]). The data were indexed and integrated by XDS/XSCALE [24], before being merged and scaled by programs in the CCP4 program suite [25]. Data collection and processing statistics are presented in Table 1.

\section{Structure determination, refinement, and analysis}

The crystal structure was determined by molecular replacement using PHASER [26] in the PHENIX program package [27] with one monomer of Orn from $X$. campestris (PDB 2GBZ; Ref.[15]) as initial search model. AutoBuiLd [28] traced the full length of one of the three monomers in the asymmetric unit, and this was subsequently fed back into PHASER, resulting in improved map quality. The manual model building was done in СООт [29] interspersed by cycles of refinement using PHENIX.REFINE [30] and converged at final $R_{\text {cryst }} / R_{\text {free }}$ values of $24.54 / 26.55$. A summary of the refinement statistics is shown in Table 1 . The atomic coordinates and structure factors have been deposited in the RCSB Protein Data Bank (www.rcsb.org) with the accession code 6RK6. Figures presented in Results section were generated using PYMOL (pymol.org).

The crystal structure of E. coli Exonuclease I (ExoI) in complex with ssDNA (PDB code 4JRP) was superpositioned onto the crystal structure of MG Orn using winCoOT [29]. Based on the corresponding bound ssDNA fragment in ExoI, a 5mer RNA fragment (CCCCC) in the A-form was generated in WinCoot and manually fitted to the MG Orn active site. Shape and charge complementarities were taken into account in the adjustment. Electrostatic surface potentials were calculated through the APBS [31] plugin in PYMOL (The PyMOL Molecular Graphics System, Version 2.0 Schrödinger, LLC). Mapping of conserved amino acids onto the molecular surface of a dimer of MG Orn was performed through the ConSurf server [32,33]. Default parameters were used, selecting 150 sequences with sequence identities in the $35-95 \%$ range. The output was visualized using PYMOL.

\section{pNP-TMP activity assay}

The time-resolved $p$ NP-TMP activity assay was performed according to Hamdan et al. [34]. In Falcon ${ }^{\circledR}$ 96-well assay plates, up to $2 \mu \mathrm{g}$ Orn was mixed with reaction buffer [50 mm Tris pH 8 (at $25{ }^{\circ} \mathrm{C}$ ), $200 \mathrm{~mm} \mathrm{NaCl}, 1 \mathrm{~mm} \mathrm{MnCl}_{2}$ ] and $1.5 \mathrm{~mm}$ thymidine $5^{\prime}$-monophosphate $p$-nitrophenyl ester sodium salt ( $p$ NP-TMP; Merck KGaA) in a total volume of $100 \mu \mathrm{L}$. The average change in absorption $(420 \mathrm{~nm})$ at $25^{\circ} \mathrm{C}$ was measured by monitoring the initial $100 \mathrm{~s}$ of each reaction using a SpectraMax ${ }^{\circledR}$ M2 ${ }^{\mathrm{e}}$ Microplate Reader (Molecular Devices, San Jose, CA, USA).

\section{Gel-based nuclease activity assay}

If not mentioned otherwise, ten microliter reactions contained $25 \mathrm{~nm}$ substrate (Table 3), $50 \mathrm{~mm}$ Tris $\mathrm{pH} 8.0$ (at $25^{\circ} \mathrm{C}$ ), $200 \mathrm{~mm} \mathrm{NaCl}$, and $1 \mathrm{~mm} \mathrm{MnCl}_{2}$. The enzyme was added in varying amounts as indicated with each figure. The enzymatic reaction took place at various incubation times and temperatures as indicated with each figure. Addition of $2.5 \mu \mathrm{L}$ of denaturing gel loading buffer $(95 \%$ formamide, $10 \mathrm{~mm}$ EDTA, $0.1 \%$ xylene cyanol) terminated the reaction after the desired incubation period. Samples were heated at $95{ }^{\circ} \mathrm{C}$ for $2 \mathrm{~min}$. Six microliter of each sample was loaded onto denaturing polyacrylamide gels $[12 \%$ or $20 \%$ polyacrylamide/7 м urea (denaturing PAA)], and gel electrophoresis

Table 3. Sequences of RNA substrates employed in the gel-based nuclease activity assay. [FAM], derivative of the fluorophore Fluorescein

\begin{tabular}{lll}
\hline $\begin{array}{l}\text { RNA } \\
\text { substrate }\end{array}$ & Sequence $\left(5^{\prime}-3^{\prime}\right)$ & Investigation of \\
\hline $5 \mathrm{mer}$ & [FAM]CCCCC & Directionality \\
$7 \mathrm{mer}$ & [FAM]CCCCCCC & Effect of salt \\
& & Effect of mutation \\
& at position 110 \\
& & Effect of reducing agent \\
& & and temperature \\
& & Effect of mutation \\
$10 \mathrm{mer}$ & [FAM]CCCCCCCCCC & at position 110 \\
& &
\end{tabular}


was performed in $1 \times$ TBE buffer ( $89 \mathrm{~mm}$ Tris, $89 \mathrm{~mm}$ boric acid, $2 \mathrm{~mm}$ EDTA) at $50 \mathrm{~W}(40 \times 20 \mathrm{~cm}$ PAA gels $)$ or $180 \mathrm{~V}(8 \times 8 \mathrm{~cm}$ PAA gels $)$ for $1 \mathrm{~h} 15 \mathrm{~min}$ to $1 \mathrm{~h} 30 \mathrm{~min}$.

Distribution of the degradation products of the endpoint activity assay was monitored by scanning the gels for FAM fluorescence (excitation at $495 \mathrm{~nm}$, emission at $517 \mathrm{~nm}$ ) in a PharosFX Plus Imager (Bio-Rad). Analysis of the gels was performed with QUANTITY ONE 1-D Analysis Software (Bio-Rad).

\section{Enzyme assay for determination of directionality}

Ten microliters of reaction contained 25 nм RNA substrate 7mer-62OMe (5'-[FAM]CCCCC $\left.[\mathrm{mC}] \mathrm{C}-3^{\prime}\right), 50 \mathrm{~mm}$ Tris $\mathrm{pH}$ 8.0 (at $25^{\circ} \mathrm{C}$ ), $150 \mathrm{~mm} \mathrm{NaCl}, 1 \mathrm{~mm} \mathrm{MnCl}_{2}, 1 \mathrm{~mm}$ DTT, $0.2 \mathrm{mg} \cdot \mathrm{mL}^{-1}$ BSA, and $2 \%$ glycerol. The reaction was started by addition of $0.74 \mu \mathrm{g}$ protein and incubated at $25{ }^{\circ} \mathrm{C}$ for 2 , 5, and $10 \mathrm{~min}$. Reactions were stopped by addition of $2.5 \mu \mathrm{L}$ denaturing gel loading buffer (95\% formamide, $10 \mathrm{~mm}$ EDTA, $0.1 \%$ xylene cyanol) and incubation at $95{ }^{\circ} \mathrm{C}$ for $5 \mathrm{~min}$. For the denaturing polyacrylamide gel electrophoresis $(12 \%$ polyacrylamide $/ 7 \mathrm{M}$ urea, $40 \times 20 \mathrm{~cm}$ ) a sample volume of $6 \mu \mathrm{L}$ was loaded onto the gel. Gel electrophoresis was performed in $0.5 \times$ TBE buffer (44.5 mM Tris, $44.5 \mathrm{~mm}$ boric acid, $1 \mathrm{~mm}$ EDTA) at $50 \mathrm{~W}$ for $1 \mathrm{~h} 15 \mathrm{~min}$, and the gel was subsequently scanned for FAM-fluorescence (excitation at $495 \mathrm{~nm}$, emission at $517 \mathrm{~nm}$ ) with the PharosFX Plus Imager (Bio-Rad).

\section{Acknowledgements}

This project was funded by the Research Council of Norway (NRC), under Grant No. 174885.

\section{Conflict of interest}

The authors declare no conflict of interest.

\section{Author contributions}

YP has been primarily responsible in planning the experiments, performed experiments such as testing the directionality of $\mathrm{Mg}$ Orn, analyzed data, and contributed to writing the paper. KB has been involved in planning and performed experiments such as mutagenesis of $\mathrm{Mg}$ Orn, protein production of OrnC110A and OrnC110G, and comparison studies of the mutants to the wild-type enzyme. She contributed to writing the paper. DPK has been involved in planning and performed experiments such as cloning of $\mathrm{Mg}$ Orn, protein production, purification and crystallization of $\mathrm{Mg}$ Orn, and basic characterization thereof. IL has been responsible for three-dimensional structure determination of $\mathrm{Mg}$ Orn, analysis thereof, and writing the paper. ANL had the original project idea, has been involved in planning experiments and analyzing data, and was primarily responsible for writing the paper.

\section{Data accessibility}

Oligoribonuclease (EC 3.1.13.3), PDB code 6RK6.

\section{References}

1 Liao H, Liu M and Guo X (2018) The special existences: nanoRNA and nanoRNase. Microbiol Res 207, 134-139.

2 Zuo Y and Deutscher MP (2001) Exoribonuclease superfamilies: structural analysis and phylogenetic distribution. Nucleic Acids Res 29, 1017-1026.

3 Ghosh S and Deutscher MP (1999) Oligoribonuclease is an essential component of the mRNA decay pathway. Proc Natl Acad Sci USA 96, 4372-4377.

4 Jacobs MA, Alwood A, Thaipisuttikul I, Spencer D, Haugen E, Ernst S, Will O, Kaul R, Raymond C, Levy $\mathrm{R}$ et al. (2003) Comprehensive transposon mutant library of Pseudomonas aeruginosa. Proc Natl Acad Sci USA 100, 14339-14344.

5 Nguyen LH, Erzberger JP, Root J and Wilson DM III (2000) The human homolog of Escherichia coli Orn degrades small single-stranded RNA and DNA oligomers. J Biol Chem 275, 25900-25906.

6 Goldman SR, Sharp JS, Vvedenskaya IO, Livny J, Dove SL and Nickels BE (2011) NanoRNAs prime transcription initiation in vivo. Mol Cell 42, 817-825.

7 Cohen D, Mechold U, Nevenzal H, Yarmiyhu Y, Randall TE, Bay DC, Rich JD, Parsek MR, Kaever V, Harrison JJ et al. (2015) Oligoribonuclease is a central feature of cyclic diguanylate signaling in Pseudomonas aeruginosa. Proc Natl Acad Sci USA 112, 11359-11364.

8 Orr MW, Donaldson GP, Severin GB, Wang J, Sintim HO, Waters CM and Lee VT (2015) Oligoribonuclease is the primary degradative enzyme for $\mathrm{pGpG}$ in Pseudomonas aeruginosa that is required for cyclic-diGMP turnover. Proc Natl Acad Sci USA 112, E5048E5057.

9 Chen G, Zhao Q, Zhu F, Chen R, Jin Y, Liu C, Pan X, Jin S, Wu W and Cheng Z (2016) Oligoribonuclease is required for the type III secretion system and pathogenesis of Pseudomonas aeruginosa. Microbiol Res 188-189, 90-96.

10 Chen F, Chen G, Liu Y, Jin Y, Cheng Z, Liu Y, Yang $\mathrm{L}$, Jin $\mathrm{S}$ and $\mathrm{Wu} \mathrm{W}$ (2017) Pseudomonas aeruginosa oligoribonuclease contributes to tolerance to ciprofloxacin by regulating pyocin biosynthesis. Antimicrob Agents Chemother 61(3), 1-11.

11 Niyogi SK and Datta AK (1975) A novel oligoribonuclease of Escherichia coli. I. Isolation and properties. J Biol Chem 250, 7307-7312. 
12 Park AY, Elvin CM, Hamdan SM, Wood RJ, Liyou NE, Hamwood TE, Jennings PA and Dixon NE (2008) Hydrolysis of the 5 '-p-nitrophenyl ester of TMP by oligoribonucleases (ORN) from Escherichia coli, Mycobacterium smegmatis, and human. Protein Expr Purif 57, 180-187.

13 Zhang X, Zhu L and Deutscher MP (1998) Oligoribonuclease is encoded by a highly conserved gene in the 3'-5' exonuclease superfamily. J Bacteriol 180, 2779-2781.

14 Datta AK and Niyogi K (1975) A novel oligoribonuclease of Escherichia coli. II. Mechanism of action. J Biol Chem 250, 7313-7319.

15 Chin KH, Yang CY, Chou CC, Wang AH and Chou SH (2006) The crystal structure of XC847 from Xanthomonas campestris: a 3'-5' oligoribonuclease of DnaQ fold family with a novel opposingly shifted helix. Proteins 65, 1036-1040.

16 Lee CW, Park SH, Jeong CS, Cha SS, Park H and Lee JH (2019) Structural basis of small RNA hydrolysis by oligoribonuclease (CpsORN) from Colwellia psychrerythraea strain 34H. Sci Rep 9, 2649.

17 Krissinel E and Henrick K (2005) Detection of protein assemblies in crystals. Lect Notes Comput Sci 3695, 163-174.

18 Weslawski JM, Wiktor J, Zajaczkowski M and Swerpel S (1993) Intertidal zone of Svalbard. 1. Macroorganism distribution and biomass. Polar Biol 13, 73-79.

19 Jones DT, Taylor WR and Thornton JM (1992) The rapid generation of mutation data matrices from protein sequences. Comput Appl Biosci 8, 275-282.

20 Kumar S, Stecher G, Li M, Knyaz C and Tamura K (2018) MEGA X: molecular evolutionary genetics analysis across computing platforms. Mol Biol Evol 35, 1547-1549.

21 Larkin MA, Blackshields G, Brown NP, Chenna R, McGettigan PA, McWilliam H, Valentin F, Wallace IM, Wilm A, Lopez R et al. (2007) Clustal W and Clustal X version 2.0. Bioinformatics 23, 2947-2948.

22 Ericsson UB, Hallberg BM, Detitta GT, Dekker N and Nordlund P (2006) Thermofluor-based high-throughput stability optimization of proteins for structural studies. Anal Biochem 357, 289-298.

23 Mueller U, Forster R, Hellmig M, Huschmann FU, Kastner A, Malecki P, Puhringer S, Rower M, Sparta $\mathrm{K}$, Steffien $\mathrm{M}$ et al. (2015) The macromolecular crystallography beamlines at BESSY II of the Helmholtz-Zentrum Berlin: current status and perspectives. Eur Phys J Plus 130(7), 141.

24 Kabsch W (2010) Xds. Acta Crystallogr D Biol Crystallogr 66, 125-132.

25 Winn MD, Ballard CC, Cowtan KD, Dodson EJ, Emsley P, Evans PR, Keegan RM, Krissinel EB, Leslie AG, McCoy A et al. (2011) Overview of the CCP4 suite and current developments. Acta Crystallogr D Biol Crystallogr 67, 235-242.

26 McCoy AJ, Grosse-Kunstleve RW, Adams PD, Winn MD, Storoni LC and Read RJ (2007) Phaser crystallographic software. J Appl Crystallogr 40, 658-674.

27 Adams PD, Afonine PV, Bunkoczi G, Chen VB, Davis IW, Echols N, Headd JJ, Hung LW, Kapral GJ, Grosse-Kunstleve RW et al. (2010) PHENIX: a comprehensive Python-based system for macromolecular structure solution. Acta Crystallogr D Biol Crystallogr 66, 213-221.

28 Terwilliger TC, Grosse-Kunstleve RW, Afonine PV, Moriarty NW, Zwart PH, Hung LW, Read RJ and Adams PD (2008) Iterative model building, structure refinement and density modification with the PHENIX AutoBuild wizard. Acta Crystallogr D Biol Crystallogr 64, 61-69.

29 Emsley P, Lohkamp B, Scott WG and Cowtan K (2010) Features and development of Coot. Acta Crystallogr D Biol Crystallogr 66, 486-501.

30 Afonine PV, Grosse-Kunstleve RW, Echols N, Headd JJ, Moriarty NW, Mustyakimov M, Terwilliger TC, Urzhumtsev A, Zwart PH and Adams PD (2012) Towards automated crystallographic structure refinement with phenix.refine. Acta Crystallogr D Biol Crystallogr 68, 352-367.

31 Baker NA, Sept D, Joseph S, Holst MJ and McCammon JA (2001) Electrostatics of nanosystems: application to microtubules and the ribosome. Proc Natl Acad Sci USA 98, 10037-10041.

32 Ashkenazy H, Abadi S, Martz E, Chay O, Mayrose I, Pupko T and Ben-Tal N (2016) ConSurf 2016: an improved methodology to estimate and visualize evolutionary conservation in macromolecules. Nucleic Acids Res 44, W344-W350.

33 Landau M, Mayrose I, Rosenberg Y, Glaser F, Martz E, Pupko T and Ben-Tal N (2005) ConSurf 2005: the projection of evolutionary conservation scores of residues on protein structures. Nucleic Acids Res 33, W299-W302.

34 Hamdan S, Bulloch EM, Thompson PR, Beck JL, Yang JY, Crowther JA, Lilley PE, Carr PD, Ollis DL, Brown SE et al. (2002) Hydrolysis of the 5'-pnitrophenyl ester of TMP by the proofreading exonuclease (epsilon) subunit of Escherichia coli DNA polymerase III. Biochemistry 41, 5266-5275.

\section{Supporting information}

Additional supporting information may be found online in the Supporting Information section at the end of the article. 
Fig. S1. Representative view of the coordination of the modelled $\mathrm{Mn}^{2+}$-ion in each of the MG Orn monomers. Highlighted amino acids are shown as sticks in atom colours, while the rest of the protein is shown as a cartoon with colouring scheme as for Figure 6. Indicated distances are given in $\AA$.

Fig. S2. Structure-based sequence alignment of $M G$ Orn with other determined structures of Orn homologs. The secondary structure elements of MG Orn are displayed in the top rows, where spirals and arrows depict $\alpha$-helix and $\beta$-strands, respectively. Identical residues are shown in white on red background, while highly conserved residues are shown in red. Cys110 is indicated by a black asterisk, while residues in the conserved DEDDh motif are indicated by blue triangles. PDB identifiers: 2GBZ: $X$. campestris Orn; 3TR8: C. burnetii Orn; 5CY4: A. baumannii Orn; 1J9A: H. influenzae Orn; 2IGI: E. coli Orn; 6A4A: C. psychrerythraea Orn.

Fig. S3. Representative electron density displaying the region around the intermolecular disulphide bond connecting two MG Orn monomers. The electron density map is displayed at 1.3 times the r.m.s. deviation.
Fig. S4. Purification and thermal stability of MG Orn and its variants OrnC110A and OrnC110G. (A) SDSPAGE gel showing purified proteins after the final purification step (standard marker Novex Mark 12, Thermo Fisher Scientific). The grey arrow marks the position of the proteins at approximately $21.5 \mathrm{kDa}$. (B) Thermofluor experiments showing the melting curves of MG Orn (green), OrnC110A (blue) and OrnC110G (red) in $50 \mathrm{mM}$ HEPES $\mathrm{pH}$ 7.5. The thermal unfolding was recorded from $10{ }^{\circ} \mathrm{C}$ to $90^{\circ} \mathrm{C}$, in increments of $0.3^{\circ} \mathrm{C}$ per $\mathrm{sec}$, and the fluorescence signal was plotted as a function of temperature. The table inset sums up the measured $T \mathrm{~m}$ for MG Orn and its variants.

Fig. S5. Nuclease activity of MG Orn and mutants on RNA 7mer and 10mer. RNA degradation was carried out in reaction buffer $(50 \mathrm{mM}$ Tris- $\mathrm{HCl} \mathrm{pH}$ 8.0, $200 \mathrm{mM} \mathrm{NaCl}, 1 \mathrm{mg} / \mathrm{ml}$ BSA, $5 \mathrm{mM}$ DTT, $10 \%$ glycerol, $1 \mathrm{mM} \mathrm{MnCl2}$ ) for 15 minutes reaction at $25^{\circ} \mathrm{C}$ and $37^{\circ} \mathrm{C}$ and analyzed on $20 \%$ PAA gels $(8 \times 8 \mathrm{~cm})$. Substrate concentration was $0.05 \mu \mathrm{M}$ and enzyme concentration was $1.16 \mu \mathrm{M}$. Control reactions were run without Orn.

Fig. S6. Nucleotide sequence encoding MG Orn. 